\title{
The Rapid Induction of Human Riboflavin Deficiency with Galactoflavin *
}

\author{
Montague Lane, Clarence P. Alfrey, Charles E. Menged, $\dagger$ \\ Maureen A. Doherty, and Jean Doherty \\ (From the Departments of Pharmacology and Medicine, Baylor University College of Medicine, \\ and the Veterans Administration Hospital, Houston, Texas; and the National \\ Cancer Institute, Bethesda, Md.)
}

Signs of riboflavin deficiency require many months to develop in patients placed on riboflavinrestricted diets $(1-6)$. The demonstrations that riboflavin deficiency induced by dietary restriction or riboflavin antagonists resulted in regression of rodent tumors (7-13) prompted several efforts in this laboratory to produce riboflavin deficiency in patients with neoplastic disease $(14,15)$. Riboflavin antagonists were used in these studies with the objective of producing the deficiency state rapidly, since a regimen requiring many months of dietary restriction would not lend itself to therapeutic evaluation in patients with metastatic cancer. These earlier investigations did not result in the production of clinical evidences of riboflavin deficiency or in objective demonstrations of tumor regression. The administered riboflavin antagonists, selected on the basis of their effectiveness in rats, were shown to be metabolized differently in man. The most active of these agents against rat tumors, 6,7-dimethyl-9-(2'-acetoxyethyl)-isoalloxazine, was rapidly and almost completely hydrolyzed in man, although a significant amount of the absorbed drug was excreted unchanged by rats. With the objective of producing human riboflavin deficiency, an analog was sought that would be an effective riboflavin antagonist in rodents and would be metabolized similarly in rodents and in man.

The present paper describes studies with 10-Ddulcityl-7,8-dimethyl-isoalloxazine, galactoflavin,

* Submitted for publication June 3, 1963; accepted November 5, 1963.

This investigation was supported in part by U. S. Public Health Service research grant CA 0-5630 from the National Cancer Institute and by the Anna Fuller Fund.

$\dagger$ Markle Scholar in Academic Medicine. Present address: Department of Medicine, Duke University, Durham, N. C. an analog reported to produce regression of lymphosarcoma in mice (10). Riboflavin deficiency was rapidly induced in six consecutive patients by means of galactoflavin and a semisynthetic, riboflavin-deficient, protein-rich diet. The clinical and laboratory manifestations of this deficiency state are reported. An anemia responsive to the administration of riboflavin occurred in each patient. This is believed to be the first reproducible evidence of riboflavin-deficiency anemia in man.

\section{Methods}

Selection of patients. Six male patients with inoperable neoplastic diseases participated in these studies. Five of the men weighed within $10 \%$ of their usual body weight when the study was begun; patient V.T. had lost $25 \%$ of his body weight. None of the patients had impairment of renal function as judged by routine urinalysis and blood urea nitrogen concentration. Two patients (C.R. and R.C.) had slightly elevated Bromsulphalein retention, and one (R.C.) had a slightly elevated serum alkaline phosphatase. All patients were informed of the nature and purposes of the study and were strongly motivated volunteers.

Plan of study. Patients were given a regular diet for several days during which caloric intake was estimated. Base-line clinical and laboratory observations were made. Four patients were given the following semisynthetic diet formula: dextrose, $280 \mathrm{~g}$; safflower oil emulsion, 1 $100 \mathrm{~g}$; calcium caseinate, ${ }^{2} 120 \mathrm{~g} ; 2 \%$ methyl cellulose, $100 \mathrm{ml}$; sodium chloride, $6 \mathrm{~g}$; potassium chloride, $6 \mathrm{~g}$; and water to make $1,500 \mathrm{ml}$ total volume. The $2 \%$ methyl cellulose was prepared by wetting $80 \mathrm{~g}$ methyl cellulose with $1,000 \mathrm{ml}$ water at $82^{\circ} \mathrm{C}$. The mixture was poured over $2,000 \mathrm{ml}$ ice chips and stirred constantly. Ice was added until the total volume was $4,000 \mathrm{ml}$. Each $1,000 \mathrm{ml}$ of formula provided 1,400 calories and $300 \mu \mathrm{g}$ riboflavin. A different protein source, to be described below, was used in the diet of patients B.P. and G.H. Subjects were encouraged to consume sufficient formula to equal their prestudy caloric intake. The formula,

1 Abbott Laboratories, North Chicago, I11.

2 Mead Johnson Laboratories, Evansville, Ind. 
given in 3 to 6 equal feedings, was prepared each morning, refrigerated, and mixed in a blendor before serving. L-cystine, $0.75 \mathrm{~g}$ per 1,400 calories of diet, was administered in gelatin capsules, $0.25 \mathrm{mg}$ each, to compensate for the L-cystine deficiency of casein. The formula was supplemented with a vitamin and mineral mixture. ${ }^{3}$ Vitamin $B_{12}, 15 \mu \mathrm{g}$, was injected intramuscularly every 14 days. The diet given patients B.P. and G.H. was modified to limit the riboflavin content even further. The protein source was "Vitamin Free" Casein.4 One hundred $g$ was added to the formula in place of the calcium caseinate. "Vitamin Free" Casein contained $14.5 \mathrm{~g}$ nitrogen (dry weight basis) and only $50 \mu \mathrm{g}$ riboflavin per $100 \mathrm{~g}$ casein. Sodium bicarbonate, $1 \mathrm{~N}, 71 \mathrm{ml}$ per $1,500 \mathrm{ml}$ of formula, was added to dissolve the casein, and the sodium chloride addition was reduced to 2 g per $1,500 \mathrm{ml}$. Three cups of coffee, prepared from individually packaged $2.2-\mathrm{g}$ servings of powdered coffee (15 $\mu \mathrm{g}$ of riboflavin per package), were permitted daily when requested by patients. Small servings of raw carrots and celery were given to maintain the integrity of dental structures. The patients were allowed supplements of stewed fruits for variety when they tired of the liquid diet alone. The riboflavin content of these servings was determined from tables of standard food values (16).

Galactoflavin 5 administration was begun shortly after the patients had adjusted to the liquid diet. Four patients received 1.5 to $3.0 \mathrm{~g}$ a day divided into 3 doses every 8 hours. Patients B.P. and G.H. received 1.5 and $3.0 \mathrm{~g}$ a day, respectively, as 6 equal doses administered 30

3 The daily vitamin and mineral supplement contained the following: vitamin $A, 5,000 \mathrm{U}$; vitamin $\mathrm{D}, 1,000 \mathrm{U}$; thiamin hydrochloride, $3 \mathrm{mg}$; nicotinamide, $15 \mathrm{mg}$; pyridoxine hydrochloride, $2 \mathrm{mg}$; folic acid, $5 \mathrm{mg}$; cyanocobalamin, $1 \mu \mathrm{g}$; calcium pantothenate, $5 \mathrm{mg}$; ascorbic acid, $75 \mathrm{mg} ; d$ - $\alpha$-tocopheryl acid succinate, $5 \mathrm{mg}$; cobaltous chloride. $6 \mathrm{H}_{2} \mathrm{O}, 2 \mathrm{mg}$; ferrous sulfate, $22 \mathrm{mg}$; cupric sulfate $5 \mathrm{H}_{2} \mathrm{O}, 4 \mathrm{mg}$; potassium iodide, $0.2 \mathrm{mg}$; manganous sulfate $5 \mathrm{H}_{2} \mathrm{O}, 1.5 \mathrm{mg}$; sodium molybdate $2 \mathrm{H}_{2} \mathrm{O}$, $0.5 \mathrm{mg}$; zinc sulfate. $7 \mathrm{H}_{2} \mathrm{O}, 5.3 \mathrm{mg}$; magnesium sulfate $7 \mathrm{H}_{2} \mathrm{O}, 61 \mathrm{mg}$.

4 Nutritional Biochemicals Corp., Cleveland, Ohio.

5 Galactoflavin (10-D-dulcityl-7,8-dimethyl-isoalloxazine) used in these studies was generously provided by $\mathrm{Dr}$. Augustus Gibson, Merck \& Co., Inc., Rahway, N. J., through the Cancer Chemotherapy National Service Center. minutes before each feeding. Oral administration was employed because the limited solubility of galactoflavin precluded adequate parenteral therapy. Doses greater than $3 \mathrm{~g}$ a day had been associated with nausea and did not result in larger urine flavin recovery in previous clinical pharmacology studies (17). Galactoflavin therapy was continued through the entire study, including the period of riboflavin supplementation (reversal of deficiency). Patients V.T., C.R., and R.C. were given kanamycin sulfate or neomycin sulfate based on speculation that deficiency might develop more rapidly if synthesis of riboflavin by intestinal bacteria could be suppressed. These drugs were given orally, $0.25 \mathrm{~g}$ four times daily. Patients S.H., B.P., and G.H. were not given antibiotics. Patients were examined daily with emphasis on the condition of the eyes, skin, lips, tongue, oral mucous membranes, and nervous system. Slit-lamp examinations were performed once a week. Photographs were taken before study, at the height of deficiency, and after administration of riboflavin.

Laboratory studies. Routine hematologic and chemical determinations were performed by the clinical laboratories. The technique of Brecher and Schneiderman was employed for reticulocyte enumeration (18). Serum electrophoresis ${ }^{6}$ was performed, and vitamin A and betacarotene in serum ${ }^{7}$ and serum $B_{12}$ levels ${ }^{8}$ were determined. Riboflavin (19), folic acid (20), and pantothenate (21) were determined by microbiological methods after acid hydrolysis of urine and growth were estimated turbidometrically. ${ }^{9}$ Urinary galactoflavin was measured fluorometrically $(14,15)$. The radioactivity of plasma was determined at frequent intervals for 8 hours after iv injection of $10 \mu \mathrm{c}$ of $\mathrm{Fe}^{50}$ globulin. The labeled globulin was prepared by addition of ferrous ${ }^{50}$ citrate to AB negative plasma from normal donors. The amount of iron added to the plasma did not exceed the iron binding capacity. One-ml samples of whole blood and plasma were counted in a single channel pulse-height analyzer ${ }^{10}$ to a maximal counting error of $3.5 \%$. All counts were corrected for background radioactivity and physical decay. The counts per minute per milliliter of plasma

${ }^{6}$ Performed by Dr. John L. Fahey.

7 Determined by Dr. John Sieri.

8 Determined by Dr. Donald Watkin.

${ }^{9}$ Dehydrated bioassay media were obtained from Difco Laboratories, Detroit, Mich.

10 Nuclear-Chicago Corp. Des Plaines, Ill.

TABLE I

Data on patients

\begin{tabular}{|c|c|c|c|c|c|}
\hline Patient & Age & Sex & Usual weight & Admission weight & Diagnosis \\
\hline & years & & $k g$ & $k g$ & \\
\hline V.T. & 35 & Male & 72 & 54 & Carcinoma of lung \\
\hline S.H. & 60 & Male & 70 & 70 & Chronic lymphocytic leukemia \\
\hline C.R. & 45 & Male & 78 & 78 & Malignant melanoma \\
\hline R.C. & 38 & Male & 100 & 96 & Teratocarcinoma testis \\
\hline B.P. & 58 & Male & 73 & 66 & Carcinoma of lung \\
\hline G.H. & 59 & Male & 59 & 59 & Carcinoma of colon \\
\hline
\end{tabular}




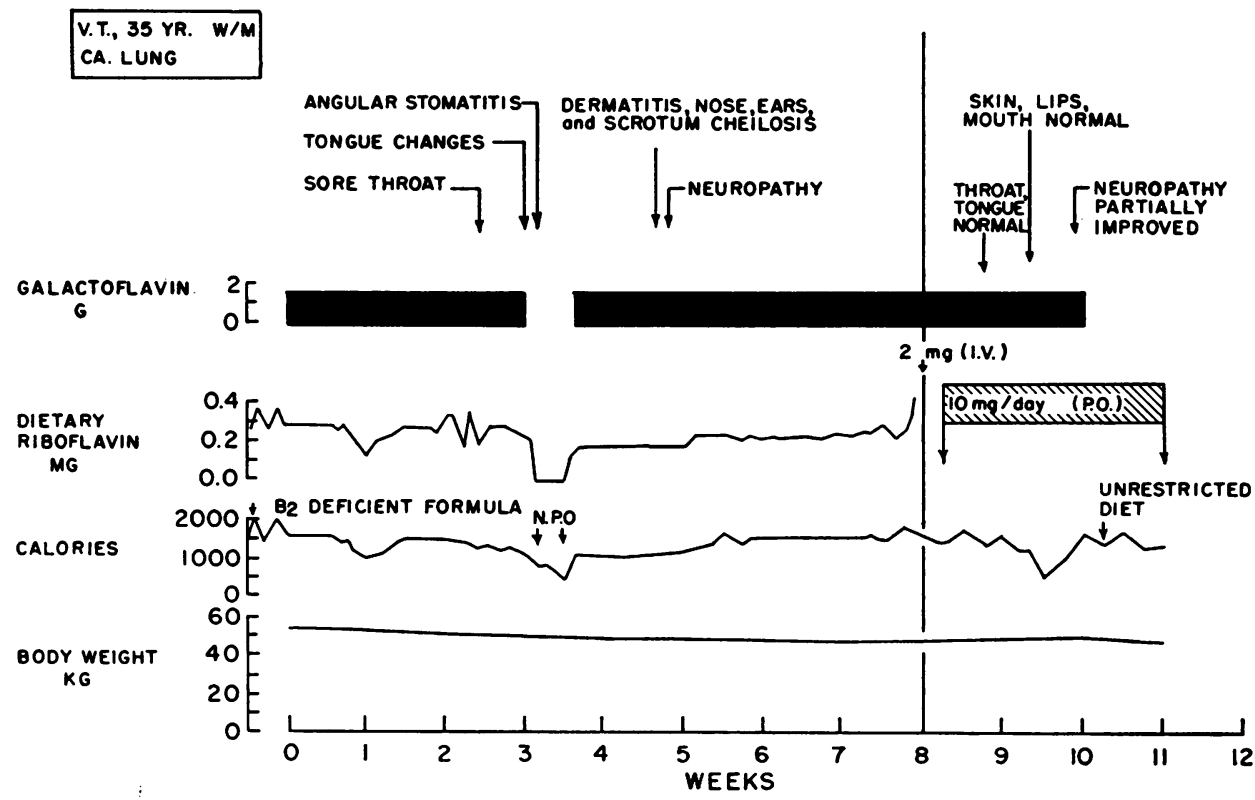

Fig. 1. Course of Development and ReVersal of riboflavin deficiency of patient V.T.

were plotted on semilogarithmic paper, and the time required for a $50 \%$ decrease in activity was determined. This value is expressed as the plasma iron clearance rate.

\section{Results}

\section{A) Clinical courses}

Essential details of the patients in the study are shown in Table I. The time of appearance of the various signs of riboflavin deficiency for the patients is shown in Figures 1 to 6 . Pertinent information for facilitation of the interpretation of the figures and significant related data are included in brief case summaries in the Appendix.

\section{B) Clinical signs of deficiency}

Oral mucosa. Five of six patients complained of sore throat. In 3 cases this was the earliest evi-

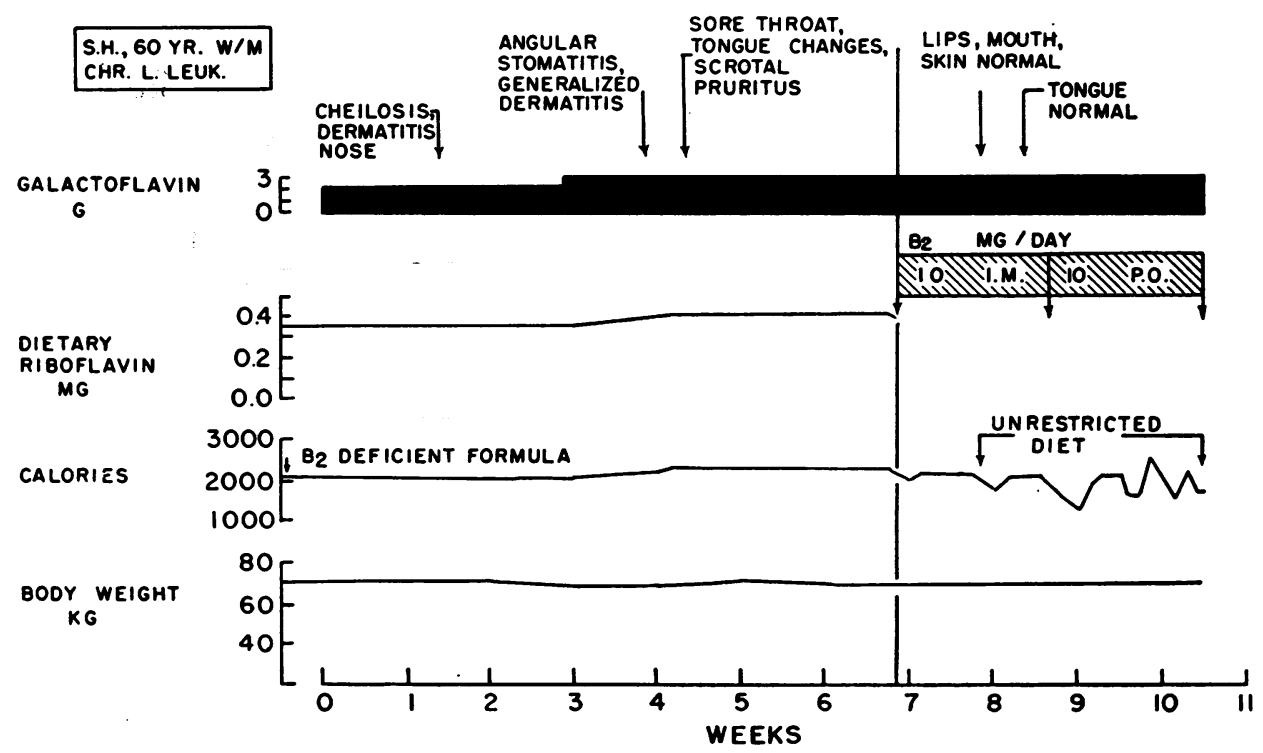

Fig. 2. Course of development and ReVersal of Riboflavin deficiency of Patient S.H. Note constancy of body weight. 


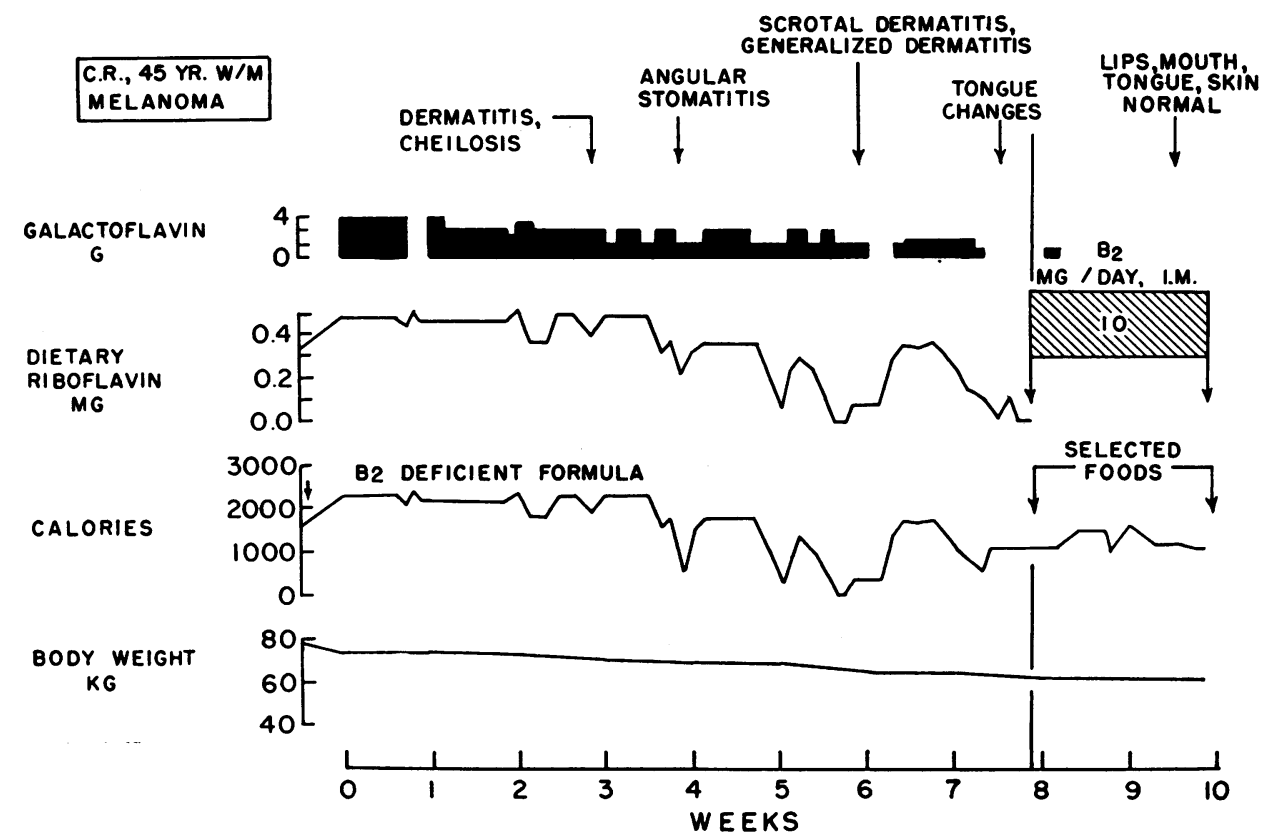

Fig. 3. Course of development and reversal of riboflavin deficiency of patient C.R. Fall in caloric intake and body weight were concomitant with progressive growth of tumor.

dence of deficiency. Characteristically patients complained of dryness and soreness of the throat on awakening but noted subsidence of discomfort during the day. The throat symptoms were not distressing. The posterior pharynx, fauces, and uvula became diffusely erythematous and edematous, and occasionally the buccal mucosa was involved. With rare exception repeated throat cul-

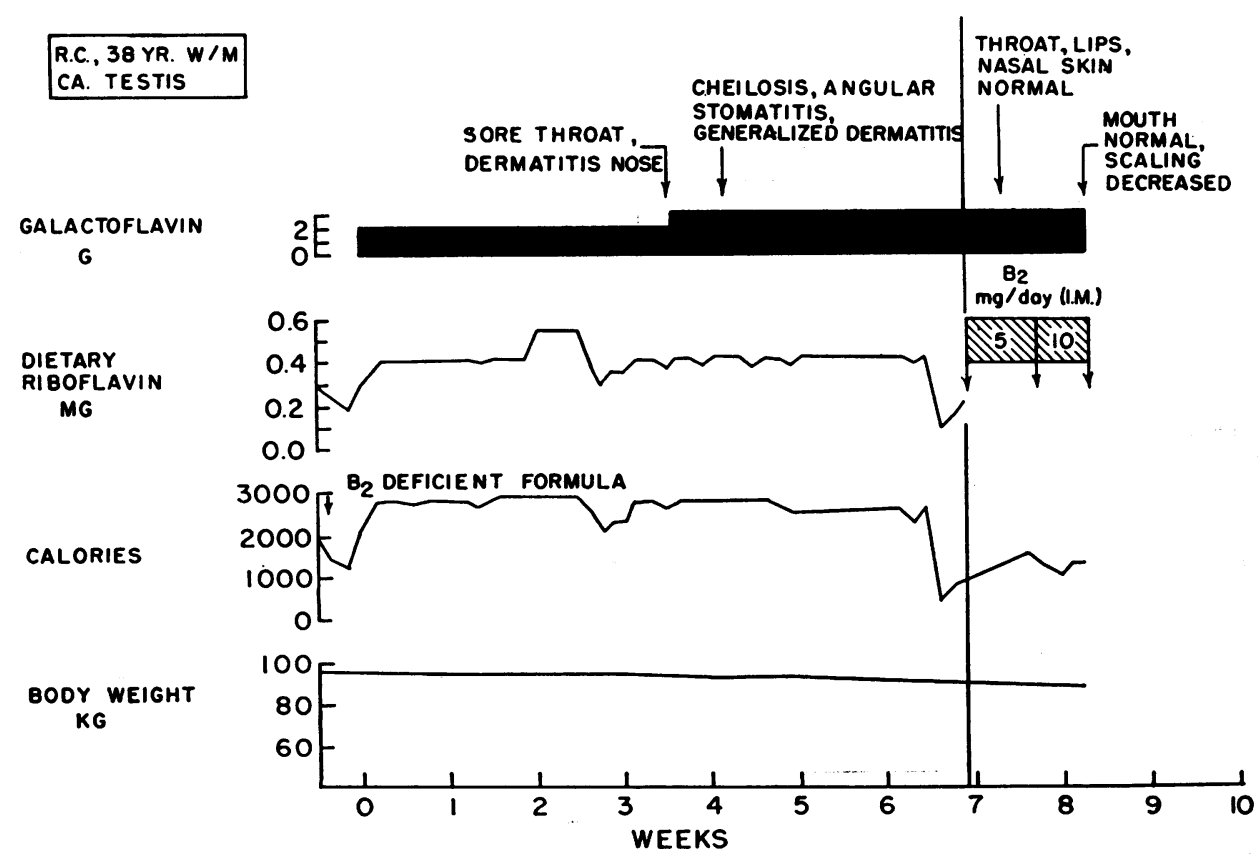

Fig. 4. Course of DeVelopment and reversal of riboflavin deficiency of patient R.C. 


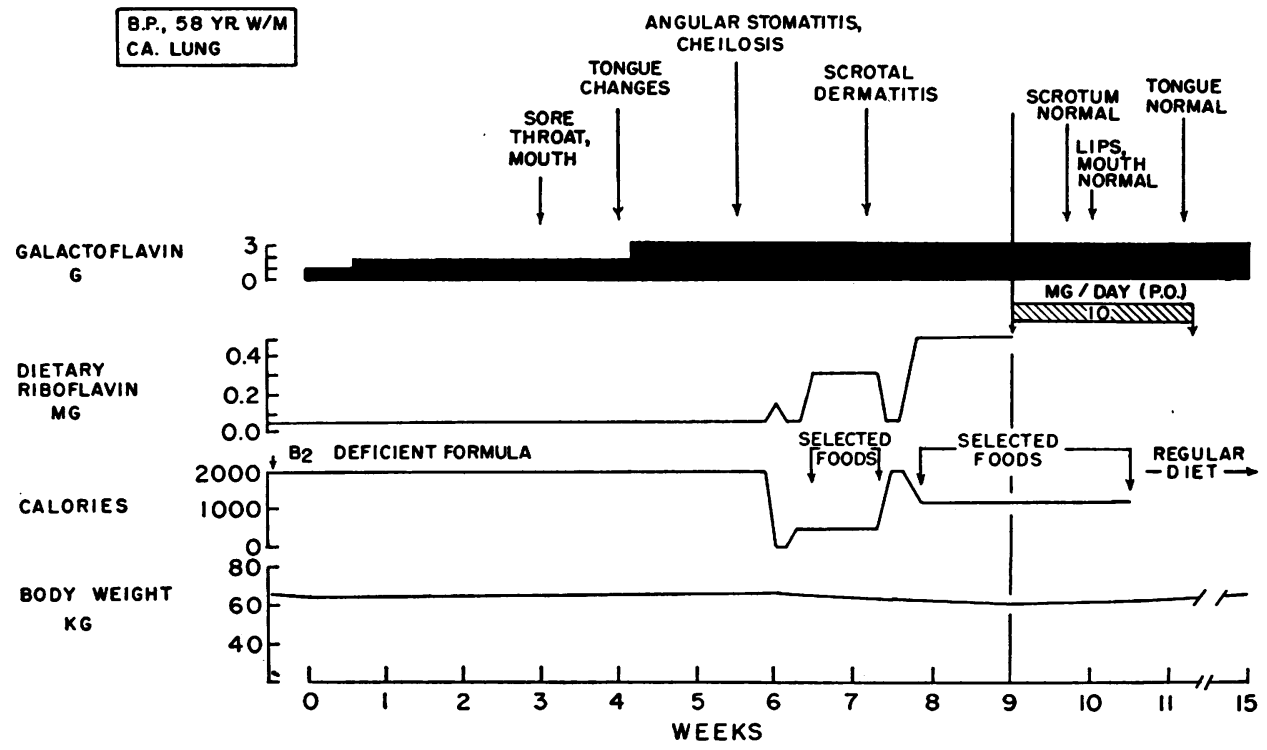

Fig. 5. Course of DeVelopment and ReVersal of Riboflavin deficiency of Patient B.P. This patient experienced relief of pain from pulmonary hypertrophic osteoarthropathy. Body weight was well maintained.

tures revealed normal bacterial flora. Candida albicans was recovered sporadically but disappeared after saline gargles.

Lips and mouth. Cheilosis developed in every patient after 10 to 38 days of galactoflavin administration. Angular stomatitis occurred in each patient, but there was no obvious relation between the time of appearance of cheilosis and of angular stomatitis. The vermilion border of the lips became dry. The superficial epithelium appeared "flaky"; at the corners of the mouth vertical fissures developed and occasionally bled. They were often several millimeters deep (Figure 7), and patients complained that the fissures were es-

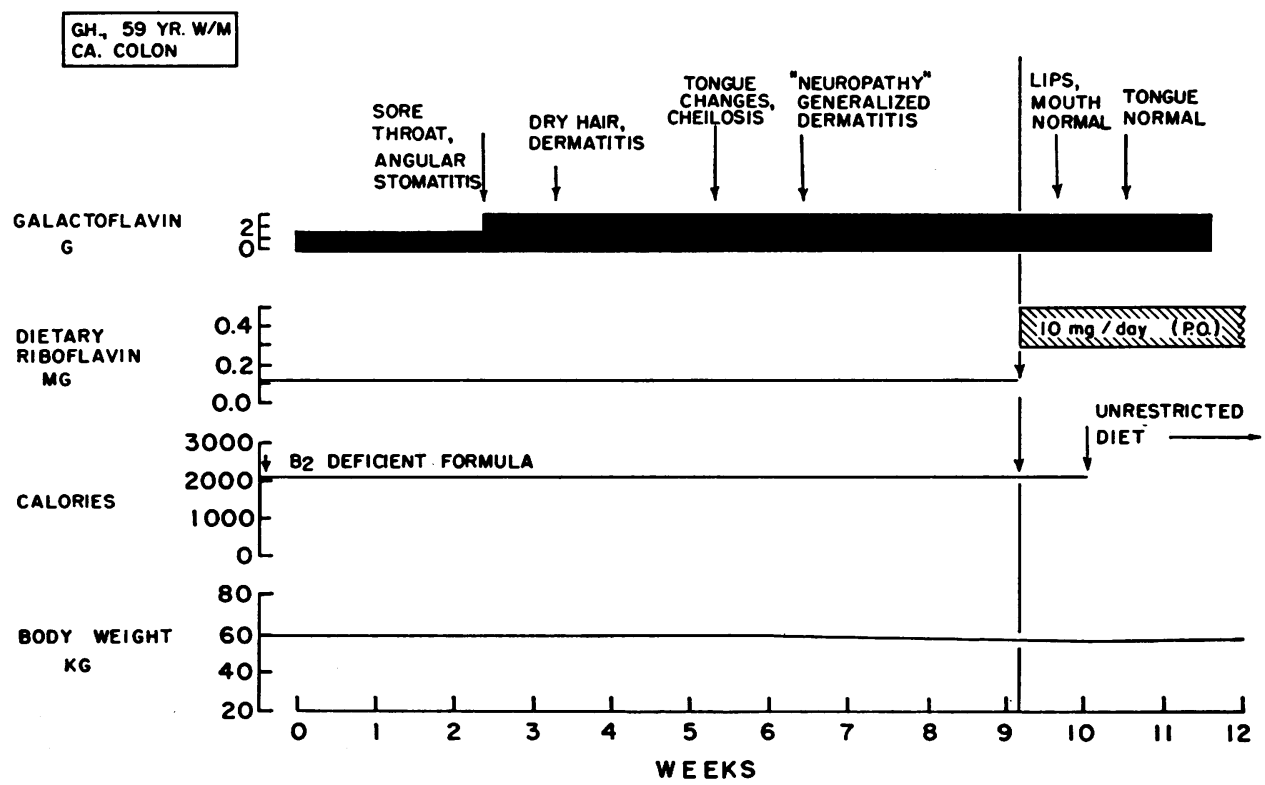

Fig. 6. Course of development and reversal of Riboflavin deficiency of patient G.H. Body weight remained constant. This patient showed objective evidence of tumor regression. 
pecially painful when eating and yawning, when they would split opes. Lip discomfort was easily relieved by the appication of petrolatum.

Tongue. Five patients developed glossitis after 21 to 53 days of galactoflavin administration. Filiform papillae flattened and disappeared first from the tips and edges of the tongue and then from the dorsum. The fungiform papillae hypertrophied and assumed a mushroom shape. In some instances the papillae appeared "cystic." The surface of the tongue was smooth except where "pebbled" by hypertrophied fungiform papillae. The tongues were slightly edematous and beefy red to magenta in color (Figure 7). One patient complained of loss of taste and could not distinguish test substances. The others had varying degrees of burning sensations that were never severe.

Skin. Each patient developed dermatitis. This consisted of drying and scaling of the epidermis, perhaps best characterized as seborrheic dermatitis. These changes first appeared on the nose, cheeks, nasolabial folds, and behind the ears. The postauricular skin was often slightly erythematous. One patient complained of dry hair. Patient B.P. had marked seborrhea of the face and scalp before study; therefore, changes in these areas could not be evaluated.

Five patients developed seborrheic dermatitis of the scrotal skin. The anterior surface of the scrotum was most severely involved bilaterally, although the median commissure was spared. Erythema and scaling were common, and the skin often appeared somewhat macerated. Pruritus and burning were frequent symptoms that were probably aggravated by the warmth and perspiration of the groin. Symptoms were relieved by $1 \%$ hydrocortisone ointment, but this did not modify the appearance of the skin.

A general dryness of the skin, which developed small, "flaky" scales, occurred in 4 patients, especially over the trunk and lower extremities. These changes were asymptomatic.

Hematological findings. A striking observation in each case was the development of anemia ( Table II). In the first 4 patients studied the mean fall in hemoglobin concentration was $3.2 \mathrm{~g}$ per $100 \mathrm{ml}$ from the start of galactoflavin administration until riboflavin therapy was instituted. Reticulocytes decreased from a mean of $1.15 \%$ (range, 0.6 to $1.6 \%$ ) to $0.28 \%$ (range, 0.2 to
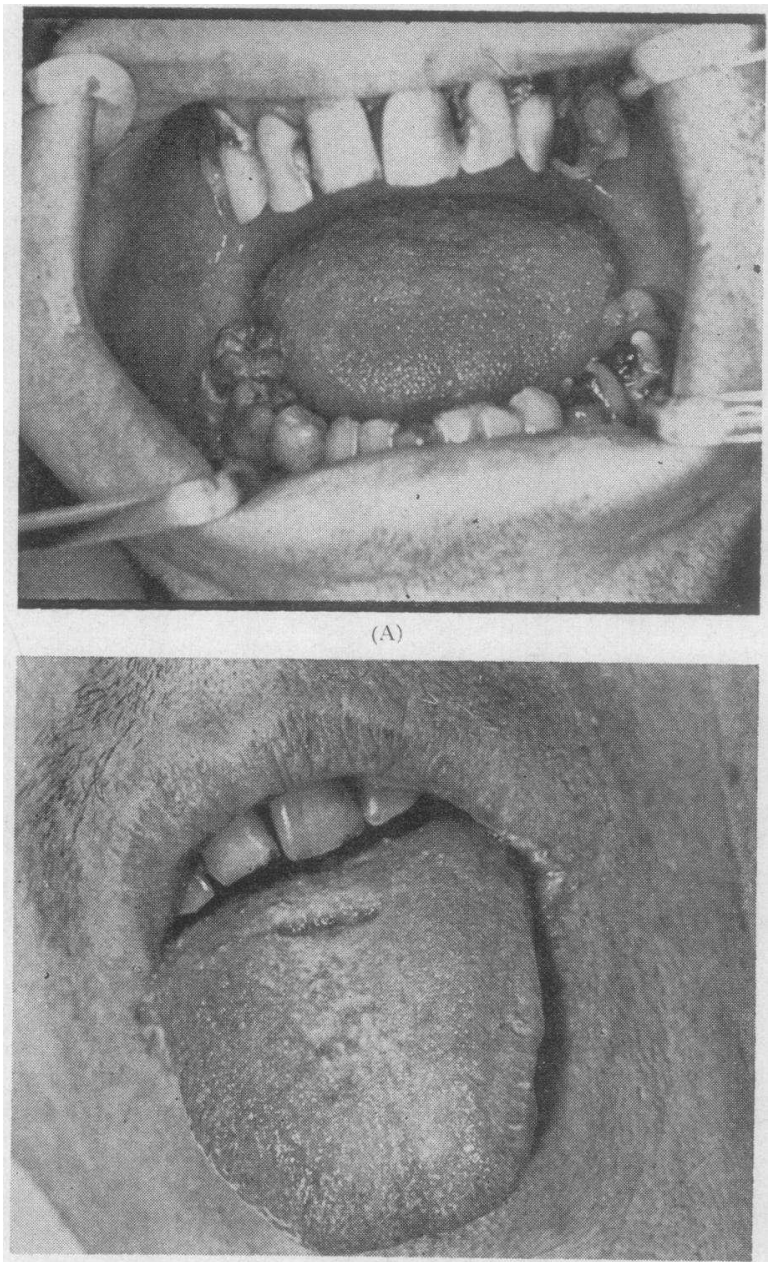

(B)

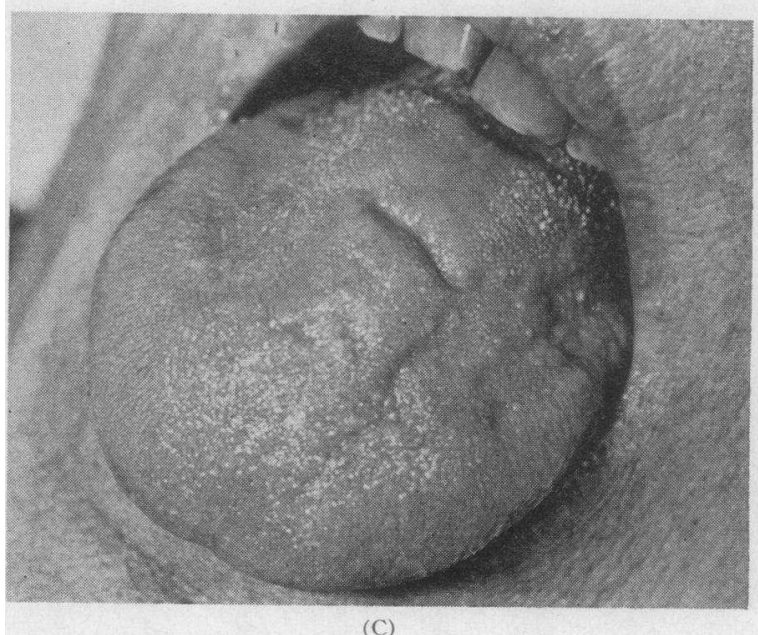

Fig. 7A. Development of glossitis in patient V.T. a) Prestudy. b) Day 44. Note absence of filiform papillae, hypertrophic fungiform papillae, and angular stomatitis. Tongue was "beefy" in color. c) Eighth day of riboflavin "therapy. Note normal papillation of tongue and disappearance of angular stomatitis. 

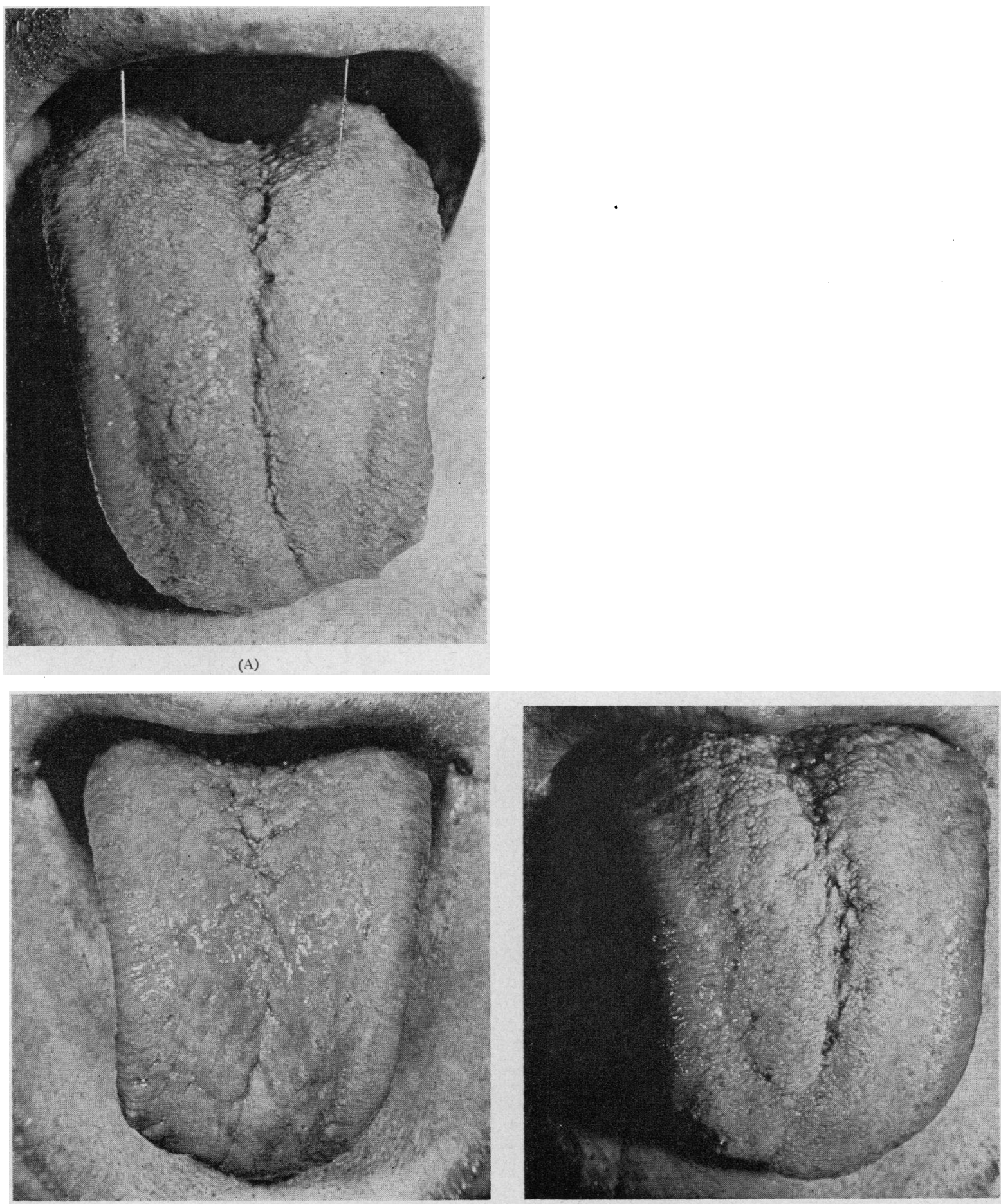

(B)

(C)

Fig. 7B. Development of glossitis in patient G.H. a) Prestudy. b) Day 49. Note basence of filiform papillae, hypertrophic fungiform papillae, angular stomatitis, and cheilosis. Tongue was magenta. c) Tenth day of riboflavin therapy. Note return of tongue and mouth to normal. 
TABLE II

Hematological effects of induced riboflavin deficiency

\begin{tabular}{|c|c|c|c|c|c|c|c|c|c|c|c|c|}
\hline \multirow{3}{*}{ Patient } & \multicolumn{5}{|c|}{ Reticulocytes } & \multicolumn{4}{|c|}{ Hemoglobin } & \multicolumn{3}{|c|}{ Plasma iron clearance rate $\left(t \frac{1}{2}\right) *$} \\
\hline & \multirow{2}{*}{$\frac{\text { Initial }}{\%}$} & \multicolumn{2}{|c|}{$\begin{array}{l}\text { Height of } \\
\text { deficiency }\end{array}$} & \multicolumn{2}{|c|}{$\begin{array}{l}\text { Riboflavin } \\
\text { reversal }\end{array}$} & \multirow{2}{*}{$\frac{\text { Initial }}{\substack{\mathrm{gl} \\
\mathrm{ml}}}$} & \multirow{2}{*}{$\begin{array}{c}\begin{array}{l}\text { Height of } \\
\text { deficiency }\end{array} \\
\mathrm{g} / 100 \mathrm{ml}\end{array}$} & \multicolumn{2}{|c|}{$\begin{array}{l}\text { Riboflavin } \\
\text { reversal }\end{array}$} & \multirow{2}{*}{$\frac{\text { Initial }}{\min }$} & \multirow{2}{*}{$\begin{array}{c}\begin{array}{c}\text { Height of } \\
\text { deficiency }\end{array} \\
\text { min }\end{array}$} & \multirow{2}{*}{$\frac{\begin{array}{c}\text { Riboflavin } \\
\text { reversal }\end{array}}{\min }-$} \\
\hline & & $\%$ & day & $\% \dagger$ & $d a y \ddagger$ & & & $\begin{array}{c}g / 100 \\
m l\end{array}$ & $\operatorname{day} \S$ & & & \\
\hline V.T. & 1.6 & 0.4 & 43 & 3.2 & 16 & 11.0 & 8.0 & 9.4 & 21 & & & \\
\hline S.H. & 1.0 & 0.2 & 50 & 2.0 & 21 & 12.1 & 9.0 & 9.3 & 21 & 82 & 173 & 53 \\
\hline C.R. & 0.6 & 0.3 & 49 & 3.0 & 10 & 12.7 & 8.5 & 8.8 & 10 & & & \\
\hline R.C. & 1.4 & 0.2 & 46 & 4.4 & 10 & 10.4 & 6.4 & 6.6 & 10 & 24 & 90 & 30 \\
\hline B.P. & 2.0 & 0.0 & 32 & 7.8 & 23 & 14.0 & 8.0 & 10.3 & 23 & 74 & 174 & 35 \\
\hline G.H. & 0.7 & 0.0 & 23 & 6.4 & 30 & 15.0 & 7.3 & 12.6 & 30 & & 298 & 58 \\
\hline
\end{tabular}

* Time in minutes for $50 \%$ reduction in radioactivity per $\mathrm{ml}$ of plasma after iv injection of $\mathrm{Fe}^{59} \mathrm{globulin}$

$\dagger$ Maximal reticulocyte response.

\pm Duration of reticulocy tosis in days.

$\S$ Last day recorded before termination of study from any cause.

$0.4 \%)$. The nadir of the reticulocyte count occurred on the average in 47 days ( 43 to 50 days). In patients B.P. and G.H., who consumed less than $125 \mu \mathrm{g}$ of riboflavin per day and were given galactoflavin before each feeding, the hemoglobin concentration fell 6.0 and $7.7 \mathrm{~g}$ per $100 \mathrm{ml}$, respectively. Reticulocytes decreased to $0 \%$ in these patients in 32 and 23 days, respectively. In 5 patients Coombs tests were negative, and osmotic fragility and serum bilirubin concentration were normal. After oral or parenteral administration of riboflavin, there was prompt reticulocytosis in each case. In the first 4 patients the peak reticulocyte response averaged $3.15 \%$, whereas in patient B.P. it was $7.8 \%$ and in G.H., $6.4 \%$. The duration of reticulocytosis varied from 10 to 30 days. There is uncertainty about these durations because reticulocyte counts were elevated when last determined (patients V.T., S.H.), and reticulocyte counts were elevated when patients were administered iron salts (C.R., R.C., and B.P.). The anemia was normochromic and normocytic. No significant changes were noted in red blood cell indexes. Examination of the bone marrow at the height of deficiency revealed depressed erythropoiesis and a paucity of late normoblasts. Riboflavin therapy resulted in marked hyperplasia of marrow erythroid cells. Significant alterations did not occur in either the leukocyte count or the platelet count, nor were obvious changes apparent in the distribution of leukocytic cells.

Iron metabolism. Consecutive serum iron determinations were performed in 3 patients. As illustrated in Figure 8, serum iron levels increased as the reticulocyte count decreased. Riboflavin administration was followed by rapid and marked decreases in the serum iron concentrations. Simultaneously, each patient developed reticulocytosis. Patients C.R. and R.C. received im iron-

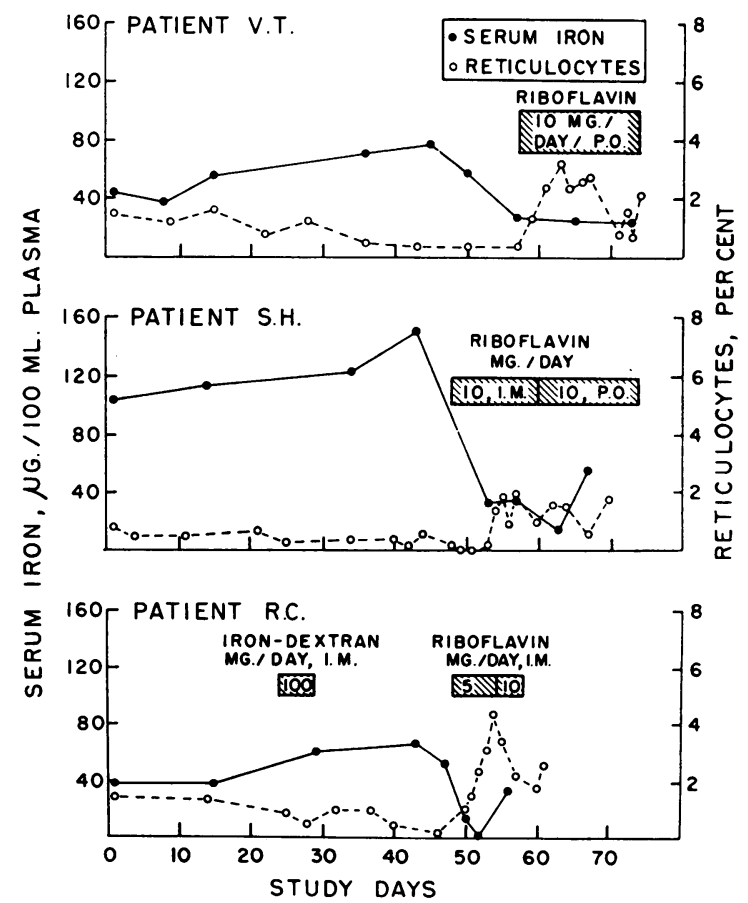

Fig. 8. EFfects of Riboflavin Deficiency AND REVERSAL OF DEFICIENCY ON SERUM IRON AND ON RETICULOCYtes in Patients V.T., S.H., and R.C. Note development of reticulocytopenia. Prompt reticulocytosis and a fall in serum iron occurred after riboflavin administration. 
dextran (1,200 and $500 \mathrm{mg}$ of elemental iron, respectively) after clinical riboflavin deficiency, anemia, and reticulocytopenia had developed. Reticulocytosis did not occur in either patient after iron administration. On the other hand, riboflavin administration produced reticulocytosis in both patients. They were again given $500 \mathrm{mg}$ of iron intramuscularly, and patient B.P. was given 1,700 $\mathrm{mg}$ as riboflavin-induced reticulocytosis subsided. These patients did not demonstrate significant reticulocyte responses to the iron injections.

As shown in Table II, the plasma iron clearance rate $\left(t \frac{1}{2}\right)$ at the height of deficiency was prolonged two to three times above control values (S.H., R.C., B.P.) and fell to or below control values upon reversal of deficiency with riboflavin. The postdeficiency radioiron study was performed in patient G.H. 7 weeks after the initiation of riboflavin therapy when the patient was on a regular diet and not receiving galactoflavin. The $\mathrm{t} \frac{1}{2}$ had fallen from 298 to 58 minutes.

Neurological findings. One patient (V.T.) developed sensory abnormalities in the upper and lower extremities compatible with the diagnosis of peripheral neuropathy. These consisted of hypalgesia, hyperesthesia, and reduced vibration and temperature appreciation below the wrists and ankles. Deep tendon reflexes were normal. Hypertrophic pulmonary osteoarthropathy was considered to be partially responsible for the neurological findings. After 3 weeks of riboflavin administration these findings were less pronounced but still present. Death occurred within the next week as a result of carcinoma of the lung.
Another patient (G.H.) developed hyperesthesia of the upper and lower extremities. No other sensory abnormalities were detected. The hyperesthesia was associated with myalgia and muscle tenderness in the extremities. These symptoms did not abate despite intensive riboflavin and multivitamin therapy.

\section{C) Laboratory observations}

Routine tests. No consistent changes were observed in the following clinical laboratory determinations: urea nitrogen, uric acid, Bromsulphalein retention, bilirubin, alkaline phosphatase, serum glutamic oxalacetic transaminase, calcium, phosphorus, sodium, potassium, or chloride. In 3 patients the serum protein decreased from 0.9 to $1.3 \mathrm{~g}$ per $100 \mathrm{ml}$ primarily due to a fall in serum albumin. The patient with chronic lymphocytic leukemia, S.H., had a $1.2 \mathrm{~g}$ per $100 \mathrm{ml}$ decrease in serum protein with no change in albumin. The serum albumin increased 0.6 and $1.4 \mathrm{~g}$ per $100 \mathrm{ml}$ in patients B.P. and G.H., respectively. Serial serum electrophoretic patterns in patients R.C. and B.P. showed changes only in albumin concentration. Serum cholesterol levels decreased in three patients. Serial determinations of the urinary 17 -hydroxycorticosteroids performed in patients V.T., R.C., and B.P. showed no appreciable changes. Stool fat determinations in patients R.C. and B.P. were repeatedly less than 6 g per day.

Vitamin determinations. a) Urine. Riboflavin and galactoflavin were determined serially in 24-

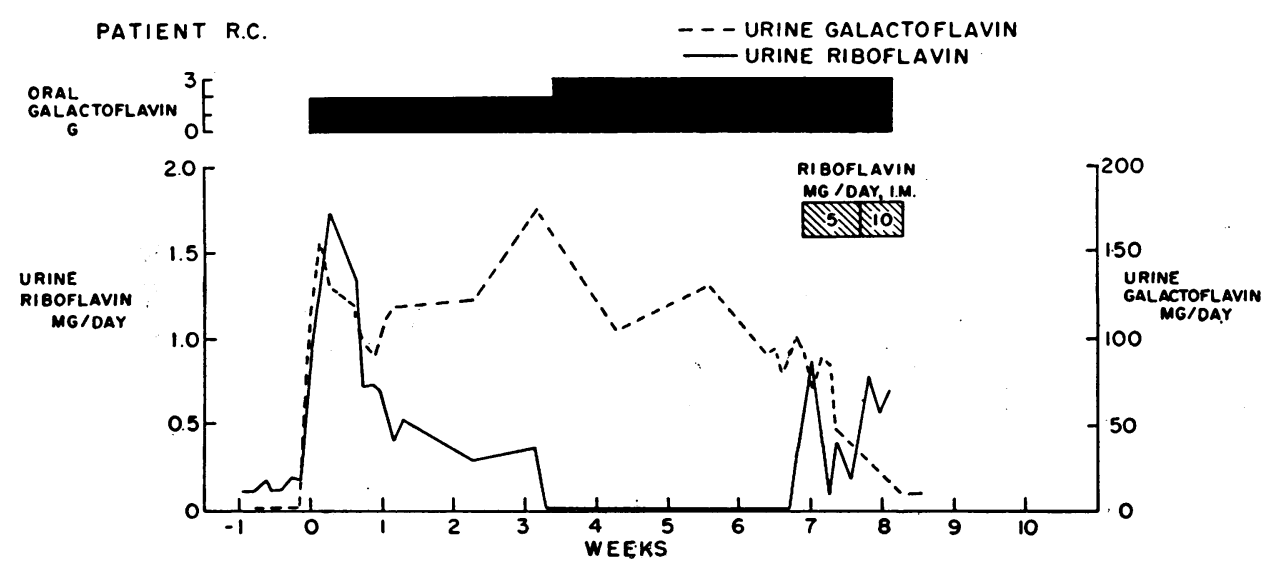

Fig. 9. Riboflavin and galactoflavin content of URine of Patient R.C. 


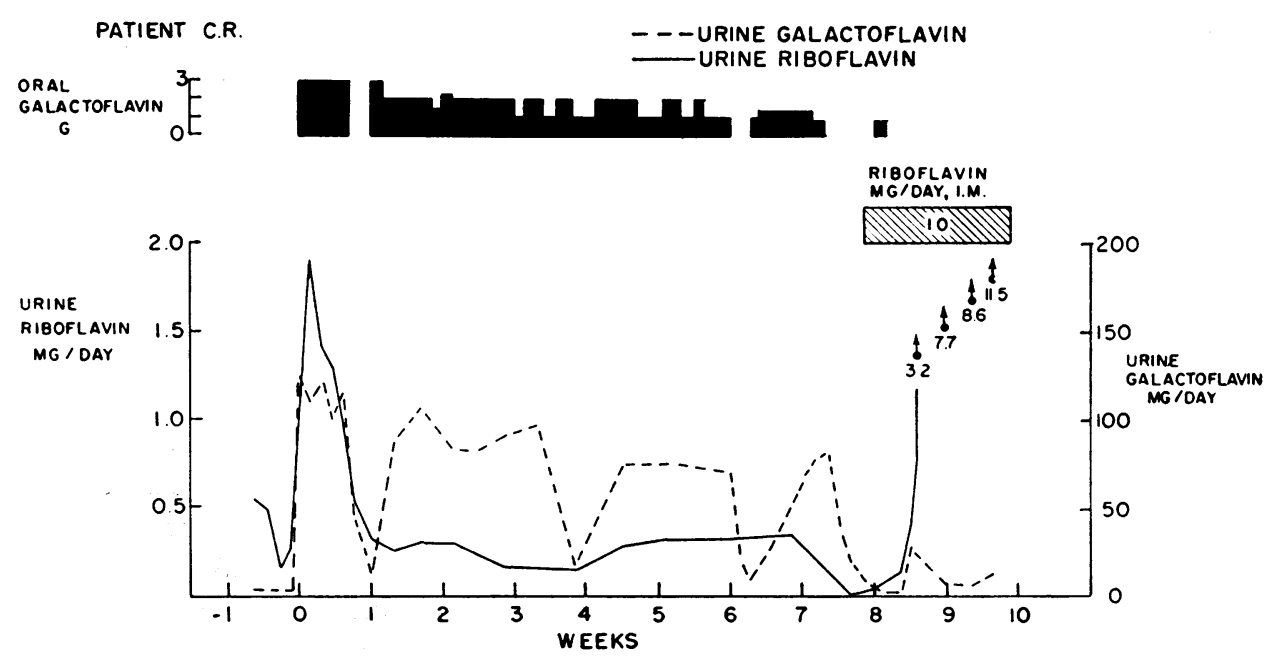

Fig. 10. Riboflavin and galactoflavin content of irine of patient C.R.

hour urine samples of 3 patients (Figures 9-11). The administration of galactoflavin was attended by an abrupt increase in riboflavin excretion from $0.2 \mathrm{mg}$ per day to peak levels of 1.7 to $2.6 \mathrm{mg}$ per day. Excretion exceeded base-line levels for 21 days (R.C.) to 50 days (B.P.) and then decreased to less than $0.08 \mathrm{mg}$ per day in each patient. The areas underlying these curves were determined planimetrically. Riboflavin excretion totaled $17.9 \mathrm{mg}$ ( $0.37 \mathrm{mg}$ per day) for patient C.R., $14.9 \mathrm{mg}$ (0.64 mg per day) for patient R.C., and $45.4 \mathrm{mg}$ (0.9 mg per day) for patient B.P. Only a small fraction of riboflavin administered orally or intramuscularly during the reversal phase appeared in the urine. Patient R.C. (Figure 9) excreted $7.2 \%$ on the first day of riboflavin therapy, $17.6 \%$ on the second day, and $8 \%$ or less of each daily dose during the next week. Patient C.R. (Figure 10) excreted 0.4 to $4.0 \%$ of riboflavin administered intramuscularly for 5 days, and then riboflavin excretion increased abruptly to 32 to $115 \%$ during the next week. Patient B.P. (Figure 11 ) excreted $8.5 \%$ of administered riboflavin on the first day and from 3.6 to $23 \%$ each day during the next 2 weeks. Galactoflavin excretion was relatively constant in each patient. On doses

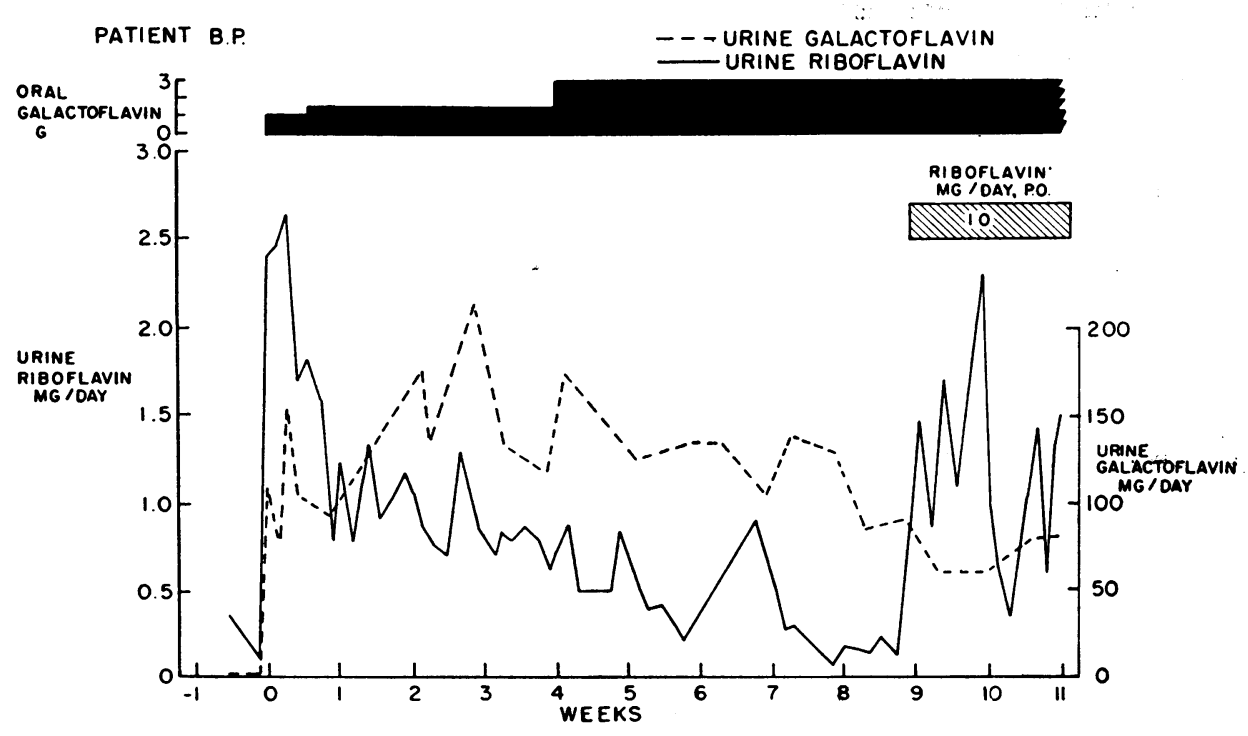

Fig. 11. Riboflavin and galactoflavin content of Urine of patient B.P. 
ranging from 1.5 to $3 \mathrm{~g}$ per day, C.R. excreted 80 to $120 \mathrm{mg}$ per day, R.C. excreted 90 to $175 \mathrm{mg}$ per day, and B.P. excreted 90 to $210 \mathrm{mg}$ per day. Galactoflavin excretion diminished in patients R.C. and B.P. during the period of riboflavin therapy.

Pantothenic acid and folic acid content of 24hour urine samples was determined for patients C.R., R.C., and S.H. The urine content of both of these vitamins did not change significantly in any patient throughout the period of study.

b) Blood. Serum vitamin A concentrations did not change (29 to $37 \mu \mathrm{g}$ per $100 \mathrm{ml}$ ) in patients R.C. and V.T., whereas beta-carotene levels decreased from 67 to $17.5 \mu \mathrm{g}$ per $100 \mathrm{ml}$ and from 55 to $20 \mu \mathrm{g}$ per $100 \mathrm{ml}$, respectively. These levels were not determined in other patients. Serum vitamin $B_{12}$ concentrations, measured in patients V.T., R.C., and S.H., ranged from 350 to $780 \mu \mu \mathrm{g}$ per $\mathrm{ml}$ throughout the studies.

\section{Discussion}

These studies were undertaken as part of a search for a riboflavin analog that would be an effective riboflavin antagonist and antitumor agent in man. In previous work, analogs effective in rodents proved incapable of producing clinical deficiency signs or tumor regression in man. It was postulated that this resulted from observed differences in drug metabolism between rats and man. The most active antagonist studied in rodents was metabolized almost entirely to less active or inactive compounds in human subjects but persisted to a significant extent in the rat. The assumption was made that if a riboflavin analog were an antagonist and antitumor agent in rodents, similar activities would probably occur in man if the pharmacological disposition and metabolism of the drug were similar in both species. Galactoflavin had been shown by others to be an effective antitumor agents in rodents (10). Pharmacological studies revealed no significant difference between the metabolism of galactoflavin in rats and human subjects. Findings suggestive of riboflavin deficiency were observed in several patients receiving galactoflavin and a diet composed of foods selected for low riboflavin content (17). These results prompted the present investigations.

There has been disagreement in the literature concerning the manifestations of riboflavin deficiency. Descriptions of lesions later attributed to lack of riboflavin were originally made in endemic (22-27) or experimentally produced (28) pellagra. Based upon these reports, the syndrome of riboflavin deficiency has been said to include cheilosis, angular stomatitis, glossitis, magenta tongue, seborrheic dermatitis of the nose and face, scrotal dermatitis, and corneal vascularization. The patients in these studies, however, suffered from multiple nutritional deficiencies and did not have "pure" riboflavin deficiency. In order to clarify the role of riboflavin, Sebrell and Butler (1) used a diet containing $0.5 \mathrm{mg}$ of riboflavin per day and produced cheilosis, angular stomatitis, and seborrhea of the face. The diet used was also deficient in niacin and other factors. Several workers have used diets containing slightly higher riboflavin contents and have been unable to confirm these findings $(2,3,29)$. Horwitt, Liebert, Kreisler, and Wittman have reported several studies in which diets providing $0.55 \mathrm{mg}$ of riboflavin per day were used. In an experiment with 15 patients, 1 patient developed cheilosis, 3 developed angular stomatitis, 3 developed seborrheic dermatitis, 12 showed scrotal dermatitis, and 3 had increased threshold for flicker fusion (15). The earliest change occurred in $4 \frac{1}{2}$ months in 1 patient, and usually signs developed in 5 to 8 months or longer. Three patients had no signs of deficiency after 15 months. Corneal vascularization, loss of papillae of the tongue, glossitis, "red" or "magenta" tongue, and neurological abnormalities were not present. A more recent study (6) with 8 patients records the following findings in 27 to 36 weeks: erythema of buccal and palatal mucosa and "beefy" redness of the tongue in 4 patients, angular stomatitis in 6 patients, scrotal dermatitis in 5 patients, and conjunctivitis and seborrheic dermatitis in 2 patients. Neither corneal vascularization, loss of tongue papillae, glossitis, nor neurological abnormalities occurred.

In the present study clinically evident riboflavin deficiency was induced rapidly in 6 consecutive subjects by means of a semisynthetic riboflavindeficient diet and galactoflavin therapy. Signs of deficiency appeared as early as 10 days after the start of galactoflavin administration and were seen in each patient no later than day 25. The resulting syndrome was more consistent, of greater 
severity, and more extensive than has been previously described in dietary deprivation studies. It was characterized by sore throat, hyperemia and edema of the pharyngeal and oral mucous membranes, cheilosis, angular stomatitis, glossitis, seborrheic dermatitis of the face and ears, scrotal dermatitis, dermatitis of the trunk and extremities, and anemia. There was no corneal vascularization or conjurctctivitis. The tongue changes (glossitis, loss of filiform papillae, hypertrophic fungiform papillae, "beefy" red to "magenta" color) were identical to those reported in clinical pellagra but not found by Horwitt and his group in experimental riboflavin deficiency. Our studies confirmed the observations by Horwitt, Harvey, Rothwell, and Cutler (6) of erythema of the buccal and palatal mucosa. However, patients with these findings in the present study complained of sore throat or mouth. In 4 patients this symptom heralded other signs of deficiency. Scrotal dermatitis was first described in pellagra $(22,28,30$ 33 ) and was verified by Hills, Liebert, Steinberg, and Horwitt (5) as an important sign of riboflavin deficiency. This was observed in 5 of 6 patients in the present study. Usually, it was one of the last signs to develop. The generalized scaling and drying of the skin of the trunk and extremities was probably indicative of severe riboflavin deficiency, but the possibility exists it was related to the high degree of unsaturation of safflower oil. This dermatitis receded after riboflavin therapy while patients were maintained on the formula and galactoflavin but was reversed more slowly than the other signs of deficiency.

Corneal vascularization has been described in the riboflavin-deficient rat (33), in the galactoflavin-treated rat (34), and in endemic deficiencies in man (35-38), which are usually complex deficiencies. It has not been produced experimentally in man. Corneal vascularization can be produced by protein deficiency (39) and amino acid deficiency (40). The specificity of this lesion in riboflavin deficiency remains controversial and is uncertain even in galactoflavin-treated animals. Its absence in the present investigations may be due to the adequacy of protein intake, to the relatively short period of deficiency, or to the absence of ocular trauma (41) suggested by Hills and associates as a factor (5). The absence of corneal vascularization in this study and in those of others
$(5,6)$ may indicate, however, that this phenomenon is not evoked in man by uncomplicated riboflavin deficiency. Elevation of flicker fusion threshold has been reported (5) but was not evaluated in the present study.

Neuropathologic changes have been described in riboflavin-deficient rats (42-43) and dogs (44) but not in man. The peripheral neuropathy observed in one of our patients (V.T.) did not reverse completely with riboflavin therapy and may have been of the variety known to occur in association with carcinoma of the lung (45). In another patient (G.H.) myalgia and hyperesthesia occurred, progressing despite intensive riboflavin and multivitamin therapy. It was probably unrelated to the deficiency state.

A very interesting finding in the present investigation was the development of anemia by all patients. Anemia has been reported in riboflavindeficient rats (46-48), pigs (49), dogs (50), and monkeys (51), but other workers have not confirmed anemia in riboflavin-deficient rats (52), pigs (53), or dogs (54). Riboflavin enhanced recovery from hemorrhage in dogs (55). Conversely, impaired recovery from hemorrhage has been observed in riboflavin-deficient rats $(48,56)$. Foy and Kondi reported a case of red cell aplasia that was believed to respond to riboflavin therapy (57). Foy, Kondi, and MacDougall recently have also reported red cell aplasia or hypoplasia in 9 of 23 cases of marasmus and kwashiorkor in Kenya (58). Five of these patients showed increases in hemoglobin and hematocrit, and 3 patients developed reticulocytosis after riboflavin administration. However, these patients were all very ill, had intercurrent infections such as pneumonia, measles, giardiasis, and tuberculosis, and received a variety of therapies. The anemia was always hypochromic, and multiple deficiencies were undoubtedly present. These authors concluded that there is "no single factor that could be regarded as a cause of these red-cell aplasias" but that they "may be associated with riboflavin deficiency.”

The present investigation demonstrated that severe riboflavin deficiency produced a normocytic, normochromic anemia, reticulocytopenia, and marrow red cell aplasia with disappearance of all but the earliest erythroid elements. No changes were noted in leukocyte or megakaryocyte precursors 
or in the peripheral granulocytes, lymphocytes, or platelets. Several investigators have stated that riboflavin deficiency had no effect upon leukopoiesis $(59,60)$, produced leukopenia $(47,61)$, leukopenia and granulocytopenia (62), or granulocytosis $(63,64)$ in rats and monkeys. No significant changes in leukocyte or differential counts were found in this study. All patients developed reticulocytosis when supplemented with riboflavin, although still on restricted diets and galactoflavin. The anemia was most severe and developed earliest in the 2 patients who received the diet made with "Vitamin Free" Casein. These patients also had the highest reticulocyte responses to riboflavin. Reticulocytopenia was associated with an increase in serum iron concentration and marked prolongation of the plasma $t \frac{1}{2}$ of injected radioiron. Riboflavin administration was followed by a fall in serum iron and a short $t \frac{1}{2}$ of radioiron. Parenteral iron supplements did not modify the hematologic findings. Riboflavin deficiency produced by dietary riboflavin restriction and galactoflavin administration affords a reproducible model for the production of reversible pure redcell aplasia in man. We have recently made these observations in rats as well (65). The normochromic, normocytic anemia of riboflavin deficiency can apparently be added to the list of B-vitamin deficiency anemias in man consisting of the megaloblastic anemias of folic acid and vitamin $\mathrm{B}_{12}$ deficiency and the hypochromic, microcytic anemia of pyridoxine deficiency. The mechanism by which riboflavin deficiency interferes with the production of red blood cells is unknown and is under investigation in this laboratory. A more detailed report of the hematologic findings is in preparation (66).

The semisynthetic diets were well tolerated. Each patient received as many or more calories as he had eaten before the study. The diet also provided adequate quantities of proteins and amino acids, fat, sodium, potassium, iron, calcium, and phosphorus. Five patients maintained their weights satisfactorily throughout the study. The patient who lost weight had frequent intercurrent illnesses and progression of his malignant disease. The vitamin and mineral supplements provided quantities equal to or in excess of recommended values and exceeded the amounts used by Hills and co-workers (5) and Horwitt and associates (6). Two (V.T., C.R.) of the 3 patients who received oral antibiotics had gastrointestinal symptoms necessitating discontinuation of these drugs after 3 and 4 weeks. The third patient (R.C.) tolerated antibiotics throughout the study. The time of onset or severity of signs of riboflavin deficiency did not appear to be influenced by antibiotic administration, although intestinal synthesis of riboflavin has been demonstrated in rats (67-69). Slight decreases in serum cholesterol have been noted in riboflavindeficient rats (70), but those observed in our patients more likely were related to the ingestion of safflower oil (71), since riboflavin therapy did not increase the serum cholesterol. The fall in beta-carotene concentration in serum reflected its virtual absence from the diet, whereas the normal serum vitamin $A$ and vitamin $B_{12}$ levels indicated that intestinal absorption of these vitamins from the supplements was adequate.

The fall in riboflavin content of the urine after institution of the riboflavin-deficient diet is in keeping with the observations of others (72). An immediate increase in riboflavin excretion to levels many times above intake of the vitamin occurred simultaneously with galactoflavin therapy. This riboflavin antagonist probably hastened the development of riboflavin deficiency by depleting the body of the vitamin. Galactoflavin can therefore be considered as a riboflavin antagonist in man. Further, it is a reversible antagonist, since all evidences of deficiency were rapidly and completely reversed by treatment with riboflavin in the face of continued galactoflavin administration. The absence of riboflavin in the urine at the height of deficiency may not have indicated zero content, since the vitamin was determined microbiologically in the presence of galactoflavin, and growth is completely inhibited at a ratio of galactoflavin to riboflavin of 625:1 (17). In any event, riboflavin excretion was very low. Further work in this laboratory has shown that galactoflavin displaces riboflavin in rat liver and that no nucleotides of the antagonist are formed. This results in marked decreases in liver flavin adenine dinucleotide and flavin mononucleotide (73). The retention of large quantities of the riboflavin administered to our patients after establishment of the deficiency reflected the magnitude of the body riboflavin deficit. The basis for the decreased galactoflavin ex- 
cretion during riboflavin therapy is uncertain, but it may be that high doses of riboflavin inhibit intestinal absorption of galactoflavin.

Patients with cancer were selected for these studies because of the report that galactoflavininduced riboflavin deficiency produced regression of mouse tumors (10). Tumor regression was noted in one of our patients, disappearance of symptoms of pulmonary hypertrophic osteoarthropathy in another, and apparent decreases in tumor growth rates in two others. Further exploration of the antitumor effects is in progress.

\section{Summary}

1. A riboflavin deficiency syndrome was induced rapidly in 6 human subjects by means of semisynthetic riboflavin-deficient diets and galactoflavin. Manifestions of the deficiency were recognizable clinically after 10 to 25 days of galactoflavin administration.

2. The deficiency syndrome was characterized by sore throat, hyperemia and edema of the pharyngeal and oral mucous membranes, cheilosis, angular stomatitis, glossitis with loss of filiform papillae and hypertrophic fungiform papillae, seborrheic dermatitis of the face and ears, scrotal dermatitis, dermatitis of the trunk and extremities, and anemia. These findings were rapidly and completely reversed after riboflavin administration.

3. Anemia and reticulocytopenia were associated with pure red cell aplasia in the bone marrow. The anemia was normochromic and normocytic. Reticulocytosis occurred promptly with riboflavin administration. Riboflavin appeared to be essential for erythropoiesis.

4. Galactoflavin was shown to be a riboflavin antagonist in man. It depleted the body of riboflavin, which was excreted in the urine in large quantities.

5. There was some evidence that galactoflavininduced riboflavin deficiency was associated with regression of human malignancies.

\section{Acknowledgment}

The authors wish to express their gratitude to Miss Lennie M. Oglesby for her assistance in the diet kitchen.

\section{Appendix}

Case V.T. (Figure 1). This patient with bronchogenic carcinoma had lost $16 \mathrm{~kg}$ in 4 months and $5 \mathrm{~kg}$ in the two weeks immediately preceding the study. During the third week of the study he developed nausea, abdominal cramps, recurrent emesis, and frequent loose stools. Oral feeding was discontinued for 3 days, and iv fluids were administered. A stool culture revealed Candida albicans and Staphylococcus aureus (coagulase positive). The diet formula and galactoflavin were then resumed, but kanamycin and neomycin were withheld. The stool flora became normal in several days. Thereafter, the liquid diet and galactoflavin were easily tolerated, and the patient maintained constant weight.

Case S.H. (Figure 2). This 60-year-old white male had a 6-year history of chronic lymphocytic leukemia. His caloric intake remained between 2,100 and 2,300 calories throughout the period of induction and reversal of deficiencies. His weight was constant during a 10week period of observation. There were no appreciable changes in leukocyte, differential, or platelet counts or in the size of the liver, spleen, or lymph nodes during the study.

Case C.R. (Figure 3). This 45-year-old white male had malignant melanoma metastatic to lymph nodes, skin, lungs, liver, and right kidney. The lesions measured less than $2 \mathrm{~cm}$. Throughout the period of study the patient's course was characterized by intermittent bouts of fever and episodes of anorexia and vomiting. Galactoflavin dosage was reduced to $2 \mathrm{~g}$ a day, on some days incorporated into the liquid diet. Maintaining the patient's oral intake after the fourth week of study became increasingly difficult, which correlated with progression of tumor. Oral antibiotics were discontinued at this time. Supplements of iv glucose and saline were required during the fifth to eighth weeks. The oral vitamin supplement was administered and retained on each day of the study. Continuation of galactoflavin administration during the reversal phase was impossible. The patient's tumors grew progressively in size and number; he lost $12 \mathrm{~kg}$ of body weight in 10 weeks.

Case R.C. (Figure 4). On admission, multiple pulmonary metastases from teratocarcinoma of the testis varying from 0.5 to $4.0 \mathrm{~cm}$ in diameter were present in the chest $\mathrm{X}$ ray. Base-line laboratory studies revealed hypochromic microcytic anemia, low serum iron, moderately impaired hepatic function, and elevated chorionic gonadotrophin titer (above 50,000 mouse units). The patient received an oral supplement of ferrous sulfate, $0.2 \mathrm{~g} 6$ times daily for 16 days. The diet and medications were well tolerated except during the reversal phase (Figure 4). Although there had been a dramatic increase in the size and number of pulmonary metastases in the month preceding the study, these lesions did not change in size during the 8 weeks of study. The chorionic gonadotrophin titers were consistently above 50,000 mouse units.

Case B.P. (Figure 5). This 58-year-old white male had received $\mathrm{X}$ irradiation to an inoperable bronchogenic carcinoma 1 year before admission. Three months before the present admission, 'he had noted for the first time the onset of generalized joint pains and intermittent swelling of the fingers of both hands. The pains were 
moderate to severe, almost constant, and aggravated by motion of the extremities. He had been taking $100 \mathrm{mg}$ of codeine sulfate by mouth every 3 hours without relief. Motion of the shoulder, elbows, wrists, and fingers was markedly restricted and associated with severe pain. The fingers of both hands were clubbed and slightly swollen, and the hands could not be closed. A chest roentgenogram revealed widening of the right superior mediastinum by an area of fibrosis. The serum uric acid was $4.1 \mathrm{mg}$ per $100 \mathrm{ml}$. Roentgenograms of the large joints and hands were normal. Several arthritic consultants agreed that the patient probably had pulmonary hypertrophic osteoarthropathy. He continued to have severe arthritis pains during the early weeks of the study. These did not respond to either codeine or sodium salicylate. Phenylbutazone, total dose, $8.3 \mathrm{~g}$, was administered between days 28 to 40 of the study but was discontinued because of lack of symptomatic improvement. Two days later the patient complained of nausea. The liver became slightly enlarged and tender for several days. Transient increases in thymol turbidity, bilirubin, and transaminase levels were noted. His joint pains began to diminish, and he was free of pain on day 50 . All joint motions in the upper extremities became normal. Since he refused to stay on the liquid diet, foods containing $500 \mu \mathrm{g}$ of riboflavin per day were substituted. Galactoflavin therapy was continued for 4 weeks beyond reversal of the tongue changes. Two weeks later, arthritic pains occurred. No changes were noted in the size of the fibrotic mass seen on chest roentgenogram.

Case G.H. (Figure 6). This 59-year-old white male had a right hemicolectomy for mucinous columnar cell carcinoma of the colon 29 months before the present admission. The patient had persistent deep perineal pain of moderate intensity and was passing stools streaked with bright red blood every day for the month before admission. He moved his bowels an average of 6 times a day. The movements were soft, dark brown, foul smelling, and small in quantity. A mass was palpated on the anterior wall of the rectum superior to the prostate gland. The mass was approximately $4 \mathrm{~cm}$ in diameter, smooth in contour, and firm; the proctoscope could not be passed beyond it. A biopsy of the mass was reported as metastatic columnar cell carcinoma. Barium enema was not remarkable. The patient's symptomatology on admission diminished during the deficiency period. Melena ceased completely, and the bowel movements became normal in number, size, shape, and consistency. He did not complain of perineal pain after the third week of study. The rectal mass decreased in size by at least $25 \%$ and developed a crater of approximately $1.5 \mathrm{~cm}$ in diameter 2 weeks before riboflavin administration. The mass increased in size 2 months later.

\section{References}

1. Sebrell, W. H., and R. E. Butler. Riboflavin deficiency in man. Publ. Hlth Rep. (Wash.) 1938, 53, 2282.

2. Williams, R. D., H. L. Mason, P. L. Cusick, and
R. M. Wilder. Observations of induced riboflavin deficiency and the riboflavin requirement of man. J. Nutr. 1943, 25, 361.

3. Keys, A., A. F. Henschel, O. Mickelsen, J. M. Brozek, and J. H. Crawford. Physiological and biochemical functions in normal young men on a diet restricted in riboflavin. J. Nutr. 1944, 27, 165.

4. Horwitt, M. K., O. W. Hills, C. C. Harvey, E. Liebert, and D. L. Steinberg. Effects of dietary depletion of riboflavin. J. Nutr. 1949, 39, 357.

5. Hills, O. W., E. Liebert, D. L. Steinberg, and M. K. Horwitt. Clinical aspects of dietary depletion of riboflavin. Arch. intern. Med. 1951, 87, 682.

6. Horwitt, M. K., C. C. Harvey, W. S. Rothwell, J. L. Cutler, and D. Haffron. Tryptophan-niacin relations in man. J. Nutr. 1956, 60 (suppl. 1).

7. Morris, H. P., and W. V. B. Robertson. Growth rate and number of spontaneous mammary carcinomas and riboflavin concentration of liver, muscle, and tumor of $\mathrm{C} 3 \mathrm{H}$ mice as influenced by dietary riboflavin. J. nat. Cancer Inst. 1943, 3, 479.

8. Emerson, G. A., and M. Tishler. The antiriboflavin effect of isoriboflavin. Proc. Soc. exp. Biol. (N. Y.) 1944, 55, 184.

9. Emerson, G. A., E. Wurtz, and O. H. Johnson. Antiriboflavin effect of galactoflavin. J. biol. Chem. 1945, 160, 165.

10. Stoerk, H. C., and G. A. Emerson. Complete regression of lymphosarcoma implants following temporary induction of riboflavin deficiency in mice. Proc. Soc. exp. Biol. (N. Y.) 1949, 70, 703.

11. Holly, F. W., E. W. Peel, R. Mozingo, and K. Folkers. Studies on carcinolytic compounds. 1. 6,7-Dichloro-9-(1'-D-sorbityl)-isoalloxazine. J. Amer. chem. Soc. 1950, 72, 5416.

12. Aposhian, H. V., and J. P. Lambooy. Retardation of growth of Walker rat carcinoma 256 by administration of diethyl riboflavin. Proc. Soc. exp. Biol. (N. Y.) 1951, 78, 197.

13. Fall, H. H., and H. G. Petering. Metabolite inhibitors. 1. 6,7-dimethyl-9-formylmethylisoalloxazine, 6,7-dimethyl-9-(2'-hydroxyethyl)-isoalloxazine and derivatives. J. Amer. Chem. Soc. 1956, 78, 377.

14. Lane, M., J. L. Fahey, R. D. Sullivan, and C. G. Zubrod. The comparative pharmacology in man and the rat of the riboflavin analogue, 6,7-dimethyl9- (2' -acetoxyethyl) -isoalloxazine, U-2112. J. Pharmacol. exp. Ther. 1958, 122, 315.

15. Lane, M., H. G. Petering, and C. O. Brindley. Synthesis, pharmacology, and clinical trial of the riboflavin analogue, sodium-6,7-dimethyl-9-(2' hemisuccinoxy-ethyl)-isoalloxazine, U-6538. J. nat. Cancer Inst. 1959, 22, 349.

16. Food, The Yearbook of Agriculture, U. S. Dept. of Agriculture. Washington, D. C., U. S. Government Printing Office, 1958.

17. Lane, M., and C. O. Brindley. In preparation. 
18. Brecher, G., and M. Schneiderman. A time-saving device for the counting of reticulocytes. Amer. J. clin. Path. 1950, 20, 1079.

19. Snell, E. E., and F. M. Strong. A microbiological assay for riboflavin. Industr. eng. Chem. anal. ed. $1939,11,346$.

20. Capps, B. F., N. L. Hobbs, and S. H. Fox. A dehydrated experimental medium for the microbiological assay of folic acid. J. Bact. 1948, 55, 869.

21. U. S. Pharmacopeia XVI, 1960, 871.

22. Stannus, H. S. Pellagra in Nyasaland (second communication). Trans. roy. Soc. trop. Med. Hyg. 1913, 7, 32.

23. Bahr, P. H. A Report on Researches on Sprue in Ceylon, 1912-1914. London, Cambridge University Press, 1915.

24. Moore, D. G. F. Partial loss of central acuity of vision for reading and for distance in school children and its possible association with food deficiency. W. Afr. med. J. 1930, 4, 46.

25. Landor, V. J., and R. A. Pallister. Avitaminosis $B_{2}$. Trans. roy. Soc. trop. Med. Hyg. 1935, 19, 121.

26. Aykroyd, W. R., and B. G. Krishnan. Stomatitis due to vitamin $B_{2}$ deficiency. Indian J. med. Res. 1936, 24, 411.

27. Moore, D. F. Retrobulbar neuritis with pellagra in Nigeria. J. trop. Med. Hyg. 1939, 42, 109.

28. Goldberger, J., and G. A. Wheeler. Experimental Production of Pellagra in Human Subjects. Hygienic Laboratory Bulletin no. 120. Washington, D. C., United States Treasury Department, U. S. Public Health Service, 1920, p. 116.

29. Horwitt, M. K., E. Liebert, O. Kreisler, and P. Wittman. Investigation of Human Requirements for B-complex Vitamins. National Research Council Bulletin no. 116. Washington, D. C., National Academy of Sciences, 1948.

30. Deiaco, P. Beitrog zur Symptomatologic der Pellagra. Wien. klin. Wschr. 1905, 17, 908.

31. Sydenstricker, V. P. The clinical manifestations of nicotinic acid and riboflavin deficiency (pellagra). Ann. intern. Med. 1941, 14, 1499.

32. Purcell, F. M. Nutritional glossitis and vitamin $B_{2}$ therapy. Trans. roy. Soc. trop. Med. Hyg. 1942, 35, 323 .

33. Bessey, O. A., and S. B. Wolbach. Vascularization of the cornea of the rat in riboflavin deficiency, with a note on corneal vascularization in vitamin A deficiency. J. exp. Med. 1939, 69, 1.

34. Kaunitz, H., H. Wiesinger, F. C. Blodi, R. E. Johnson, and C. A. Slanetz. Relation of protein and fat intake to growth and corneal vascularization in galactoflavin-produced ariboflavinosis. J. Nutr. 1954, 52, 467.

35. Spies, T. D., R. W. Vilter, and W. F. Ashe. Pellagra, beriberi and riboflavin deficiency in human beings: diagnosis and treatment. J. Amer. med. Ass. 1939, 113, 931.

36. Spies, T. D., W. B. Bean, and W. F. Ashe. Recent advances in the treatment of pellagra and associated deficiencies. Ann. intern. Med. 1939, 12, 1830.

37. Sydenstricker, V. P., L. E. Geeslin, C. M. Templeton, and J. W. Weaver. Riboflavin deficiency in human subjects. J. Amer. med. Ass. 1939, 113, 1697.

38. Kruse, H. D., V. P. Sydenstricker, W. H. Sebrell, and H. M. Cleckley. Ocular manifestations of ariboflavinosis. Publ. Hlth Rep. (Wash.) 1940, 55, 157.

39. Sydenstricker, V. P., W. K. Hall, C. W. Hock, and E. R. Pund. Amino acid and protein deficiencies as causes of corneal vascularization: a preliminary report. Science 1946, 103, 194.

40. Sydenstricker, V. P., W. K. Hall, L. L. Bowles, and H. L. Schmidt, Jr. The corneal vascularization resulting from deficiencies of amino acids in the rat. J. Nutr. 1947, 34, 481.

41. Tisdall, F. F., J. F. McCreary, and H. Pearce. The effect of riboflavin on corneal vascularization and symptoms of eye fatigue in R.C.A.F. personnel. Canad. med. Ass. J. 1943, 49, 5.

42. Shaw, J. H., and P. H. Phillips. The pathology of riboflavin deficiency in the rat. J. Nutr. 1941, 22, 345.

43. Engel, R. W., and P. H. Phillips. Effect of riboflavin-low diets upon nerves, growth, and reproduction in the rat. Proc. Soc. exp. Biol. (N. Y.) 1939, 40, 597.

44. Street, H. R., G. R. Cowgill, and H. M. Zimmerman. Further observations of riboflavin deficiency in the dog. J. Nutr. 1941, 22, 7.

45. Lennox, B., and S. Prichard. The association of bronchial carcinoma and peripheral neuritis. Quart. J. Med. 1950, 19, 97.

46. Endicott, K. M., A. Kornberg, and M. Ott. Hemopoiesis in riboflavin-deficient rats. Blood 1947, 2, 164.

47. Shukers, C. F., and P. L. Day. The effects of inanition and riboflavin deficiency upon the blood picture of the rat. J. Nutr. 1943, 25, 511.

48. Kornberg, A., H. Tabor, and W. H. Sebrell. Blood regeneration in rats deficient in biotin, thiamin or riboflavin. Amer. J. Physiol. 1945, 145, 54.

49. Wintrobe, M. M., W. Buschke, R. H. Follis, Jr., and S. Humphreys. Riboflavin deficiency in swine with special reference to the occurrence of cataracts. Bull. Johns Hopk. Hosp. 1944, 75, 102.

50. Spector, H., A. R. Maass, L. Michaud, C. A. Elvehjem, and E. B. Hart. The role of riboflavin in blood regeneration. J. biol. Chem. 1943, 150, 75.

51. Waisman, H. A. Production of riboflavin deficiency in the monkey. Proc. Soc. exp. Biol. (N. Y.) 1944, 55, 69.

52. Carpenter, K. J., and E. Kodicek. Blood pictures of pyridoxine and riboflavin-deficient rats. Int. $Z$. Vitamin-forsch. 1952, 24, 241.

53. Terrill, S. W., C. B. Ammerman, D. E. Walker, R. M. Edwards, H. W. Norton, and D. E. Becker. Riboflavin studies in pigs. J. anim. Sci. 1955, 14, 593. 
54. Axelrod, A. E., M. A. Lipton, and C. A. Elvehjem. Riboflavin deficiency in the dog. Amer. J. Physiol. 1941, 133, 555.

55. György, P., F. S. Robscheit-Robbins, and G. H. Whipple. Lactoflavin (riboflavin) increases hemoglobin production in the anemic dog. Amer. J. Physiol. 1938, 122, 154.

56. Mookerjea, S., and W. W. Hawkins. Haematopoiesis in the rat in riboflavin deficiency. Brit. J. Nutr. 1960, 14, 239.

57. Foy, H., and A. Kondi. A case of true red-cell aplastic anemia successfully treated with riboflavin. J. Path. Bact. 1953, 65, 559.

58. Foy, H., A. Kondi, and L. MacDougall. Pure redcell aplasia in marasmus and kwashiorkor treated with riboflavine. Brit. Med. J. 1961, 1, 937.

59. Guha, B. C., and L. W. Mapson. The role of certain dietary factors in the formation of erythrocytes. Biochem. J. 1931, 25, 1674.

60. Sure, B., M. C. Kik, and M. E. Smith. Hematopoietic function in avitaminosis. VI. Vitamin G deficiency. Proc. Soc. exp. Biol. (N. Y.) 1931, 28, 498.

61. Kohls, C. L. Blood picture in vitamin G deficiency. Anat. Rec. 1932, suppl. no. 1, 52, 62.

62. Kornberg, A., F. S. Daft, and W. H. Sebrell. Granulocytopenia and anemia in riboflavin-deficient rats and treatment with $L$. casei factor ("folic acid") and riboflavin. Arch. Biochem. $1945,8,431$.

63. Lecoq, R., and A. Raffy. Hematological study of rats deprived of riboflavin and of the total vitamin B complex. Bull. Soc. Chim. biol. (Paris) 1947, 29, 489.
64. Musser, E. A., and R. W. Heinle. The effect of a riboflavin antagonist upon leukocytes of normal and Shay myeloid chloroleukemic rats. Blood 1958, $13,464$.

65. Alfrey, C. P., V. E. Davis, and M. Lane. In preparation.

66. Lane, M., and C. P. Alfrey. In preparation.

67. Fridericia, L. S., P. Freudenthal, S. Gudjonnson, G. Johansen, and N. Schoubye. Refection, a transmissable change in the intestinal content, enabling rats to grow and thrive without Vitamin B in the food. J. Hyg. (Lond.) 1928, 27, 70.

68. Coates, M. E., K. M. Henry, P. M. Kon, S. Y. Kon, E. H. Mawson, J. E. Stanier, and S. Y. Thompson. Sulfonamides and potato starch refection in the rat. Nature (Lond.) 1946, 157, 262.

69. Faulkner, R. D., and J. P. Lambooy. Intestinal synthesis of riboflavin in the rat. J. Nutr. 1961, 75, 373.

70. Harrill, J., A. M. Kylen, A. Weis, and E. Dyar. Relation of dietary fat and supplementary riboflavin to tissue levels of cholesterol, riboflavin and total lipids in the rat. J. Nutr. 1959, 69, 356.

71. Kinsell, L. W., G. D. Michaels, J. W. Partridge, L. A. Boling, H. E. Balch, and G. C. Cochrane. Effect upon serum cholesterol and phospholipids of diets containing large amounts of vegetable fat. J. clin. Nutr. 1953, 1, 224.

72. Horwitt, M. K., C. C. Harvey, O. W. Hills, and E. Liebert. Correlation of urinary excretion of riboflavin with dietary intake and symptoms of ariboflavinosis. J. Nutr. 1951, 41, 247.

73. Lane, M. In preparation. 